\title{
Incidence of the Anatomical Variations of Mental Foramen in Human Mandibles of a Brazilian Sample
}

\author{
Luciane Naomi Oguma Watanabe, ${ }^{1}$ Alexandre Rodrigues Freire, ${ }^{1}$ Juliana Haddad1, Paulo Roberto Botacin, ${ }^{2}$ Felippe Bevilacqua \\ Prado, ${ }^{1}$ Ana Cláudia Rossi ${ }^{1}$
}

'Department of Biosciences, Anatomy Division, Piracicaba Dental School, University of Campinas, Piracicaba, SP, Brazil; ${ }^{2}$ Department of Basic Sciences, Araçatuba Dental School, Paulista State University, Araçatuba, SP, Brazil.

Disclose and conflicts of interest: none to be declared by all authors

\begin{abstract}
Introduction: to evaluate the incidence of accessory and double mental foramina in human mandibles from a Brazilian sample. Material and Methods: 100 dried human mandibles (29 females and 71 males) were analyzed, aged 18 to 60 years. The mandibles were evaluated on their right and left sides. The foramens were evaluated being accessory mental foramen or double mental foramen. All data were analyzed using the GraphPAD Prism v.8 software (San Diego, CA, USA). Descriptive statistics (in \%) and the chi-square test $\left(x_{2}\right)$ were performed to compare the incidence of each foramen between the sexes and the sides. The probability value $\leq 0.05$ was defined as the level of significance.

Results: of the 71 male mandibles, the incidence was $16.9 \%$ for the accessory mental foramen, and $22.53 \%$ for the double mental foramen. Of the 29 female mandibles, the incidence was $10.34 \%$ for the accessory mental foramen, and $24.13 \%$ for the double mental foramen. There were $12 \%$ of the accessory mental foramen on the right side and $3 \%$ on the left side. And $11 \%$ of the double mental foramen on the right side and $12 \%$ on the left side. The chi-square test revealed that there was no statistically significant difference for both sex ( $P$ value: 0.7066$)$ and for the side (P value: 0.0818 ).

Conclusion: the incidence of accessory and double mental foramen in the studied sample must be considered given the importance of knowledge of the anatomy of these foramina during the execution of anaesthetic and surgical procedures in Dentistry.

Keywords: Mental foramen; Anatomical variations; Anatomy; Dentistry; Mandible.
\end{abstract}

\section{Introduction}

The mental foramen (MF) is an anatomical structure located on the lateral surface of the mandibular body. It consists of a bilateral opening, in the buccal portion of the mandible, where the blood vessels and the corresponding nerve endings will exteriorize ${ }^{1}$. The MF represents the termination of the mandibular canal that opens to the surface. It is located between the roots of the lower premolars, halfway from the mandibular base and halfway from the alveolar part, and during dental procedures it is used as a reference ${ }^{1}$.

The anatomy of the MF has been studied by different methodologies: ex $v i v o^{2}$ and in $v i v o^{3}$, computed tomography and panoramic radiographs ${ }^{4}$ being it is used as the main study method, as it is not invasive during diagnoses ${ }^{5}$. There are other techniques including ultrasonography ${ }^{6}$, periapical radiographs and magnetic resonance imaging, being computed tomography superior in comparison with periapical radiographs and panoramic radiographs in image detection of the $\mathrm{MF}^{7}$.

Knowing the location of the MF will assist in the correct performance of dental procedures, such as anesthetic block, placement of implants and diagnosis of pathologies ${ }^{8,9}$. Knowing its correct location helps to prevent possible complications, preventing hemorrhage through paresthesia of the lower lip through trauma during surgical procedures ${ }^{10}$. Any clinical or surgical procedure requires precise knowledge of the location of the MF and the presence of possible accessory mental foramen (AMF).

In some cases, the MF may have additional foramen, being called AMF, and has been reported with anatomical variation ${ }^{11,12}$. The presence of AMF indicates special attention on the part of the professional in the procedure of interventions in the mandible. Studies mentioning this anatomical variation in the Brazilian population are scarce. According to Hanihara and Ishida $^{13}$, the AMF is found most commonly in Japanese and sub-Saharan Africans, ranging from $6.7 \%$ to $12.5 \%$.

AMF consists of a small foramen that communicates with the mandibular cana ${ }^{14,15}$. The MF is considered an important anatomical structure, as it is fundamental in surgical and anesthetic procedures, and its correct location is essential. In humans, the MF is predominantly unique, consisting of an opening on each side of the mandibular body, representing the end of the mandibular canal. Although it is commonly unique, it may be accompanied by accessory foramina, which may be smaller and separated from the main 
foramen through a bony septum. When the MF is doubled there may be incomplete anesthesia, which is an important clinical aspect to be considered by dentists ${ }^{16}$.

Thus, there is a need to analyze and establish the incidence of AMF in Brazilian samples, as these anatomical variations often remain unnoticed and undiagnosed, making the mental nerve block not very effective. The knowledge of its location is essential for performing dental procedures such as anesthetic blocks, dental implants and several other procedures, avoiding the risk of complications.

The aim of the study was to evaluate the incidence of anatomical variations of MF in the dry human mandibles of a Brazilian population sample.

\section{Material and Methods}

The study was approval by Piracicaba Dental School (FOP-UNICAMP) Human Research Ethics Committee. The approval number for this study is: 02615118.8.0000.5418.

\section{Sample}

100 dried human mandibles from the Biobank "Human teeth, bones and corpses" of the Piracicaba Dental School, University of Campinas(FOP- UNICAMP) were analyzed. 100 human mandibles of both sexes and in the age group 18 to 80 years were included. The mandibles with fractures or macroscopic surgical or pathological changes were excluded.

The evaluated mandibles were separated into two groups based on the sex of the individuals. The sample consisted of 29 female and 71 male mandibles.

\section{Analysis of the foramens}

The mandibles were evaluated on their right and left sides in search of the target anatomical variation.

The foramens were evaluated following the description:

- AMF: features a small foramen, which have no direct relationship between the MF, featuring different openings (Figure 1).

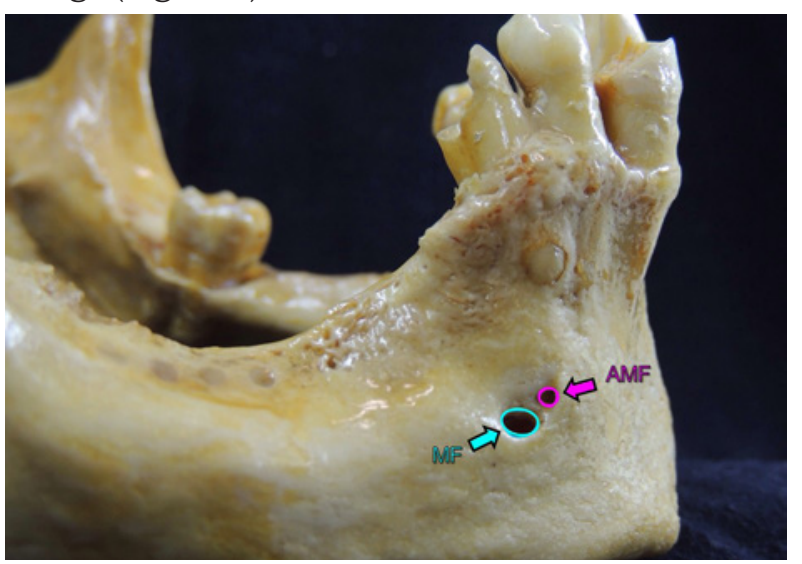

Figure 1. A) Lateral view (right side) of the adult human mandible. B) Line arts indicate the contours to visualize the MF and the AMF. Note the MF and AMF have no direct relationship between them featuring different openings.
- The double mental foramen (DMF): features dimensionally smaller than the MF and share a great common opening for both foramens (MF and DMF).

The DMF formation occurs due to the presence of a bony septum featuring two openings (Figure 2).

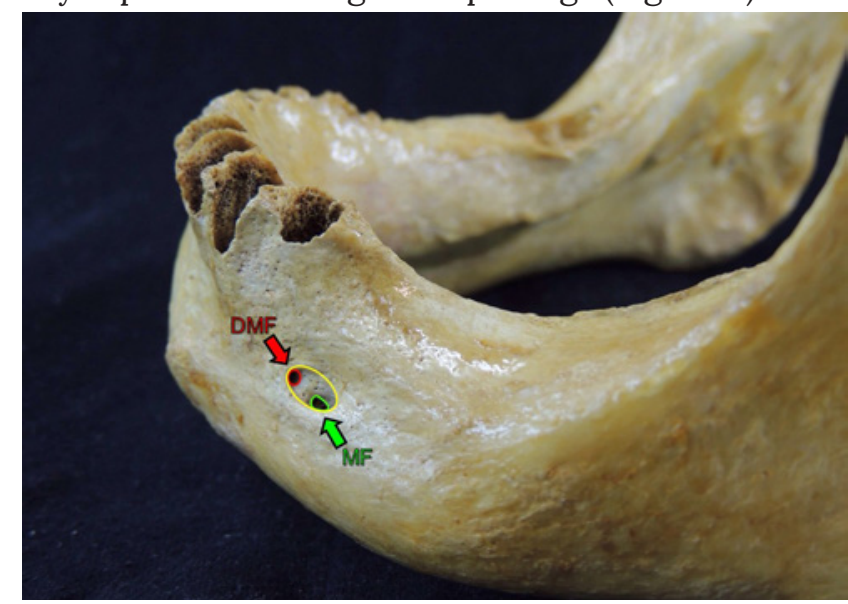

Figure 2. Lateral view (left side) of an adult human mandible. B) Line arts indicate the contours to visualize the MF and the DMF. The yellow contour indicates a great common opening for both foramens (MF and DMF). Note the DMF formation occurs due to the presence of a bony septum featuring two openings (DMF).

\section{Statistical analysis}

The data were tabulated in the Microsoft Office Excel package. Then, descriptive statistics (\%) and the chi-square test $(\chi 2)$ were performed to compare the incidence of each foramen between the sexes and the sides. The probability value $\leq 0.05$ was defined as the level of significance. The incidence of AMF on the right and left sides of the mandibles was analyzed. All data were analyzed using the GraphPAD Prism v.8 software (San Diego, CA, USA).

\section{Results}

Of the 71 male mandibles, the incidence was $16.9 \%$ for the AMF, and $22.53 \%$ for the DMF. Of the 29 female mandibles, the incidence was $10.34 \%$ for the AMF, and $24.13 \%$ for the DMF (Figure 3). There was 12\% of the AMF on the right side and $3 \%$ on the left side. And $11 \%$ of the DMF on the right side and $12 \%$ on the left side (Figure 4).

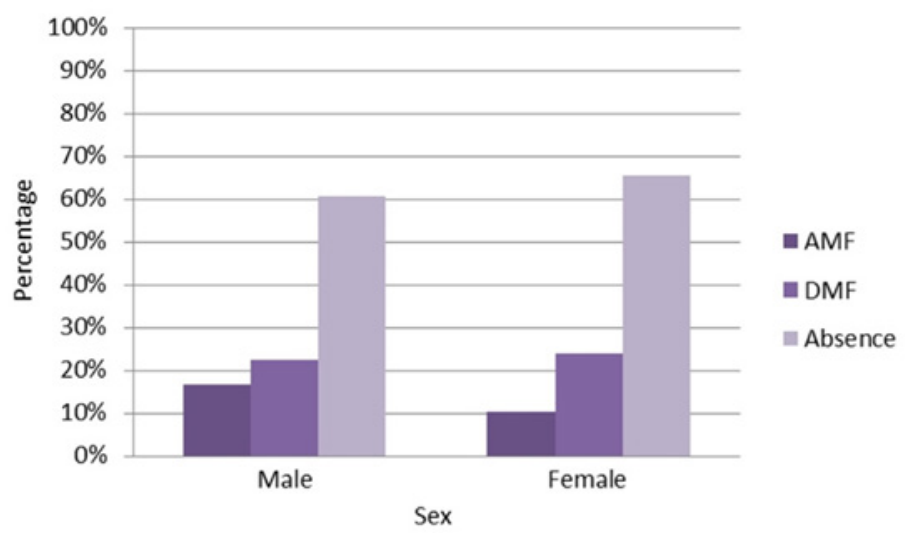

Figure 3. Distribution of types of $M F$ in relation to sex. Absence means the no presence of DMF and / or AMF. AMF: accessory mental foramen; DMF: double mental foramen. 


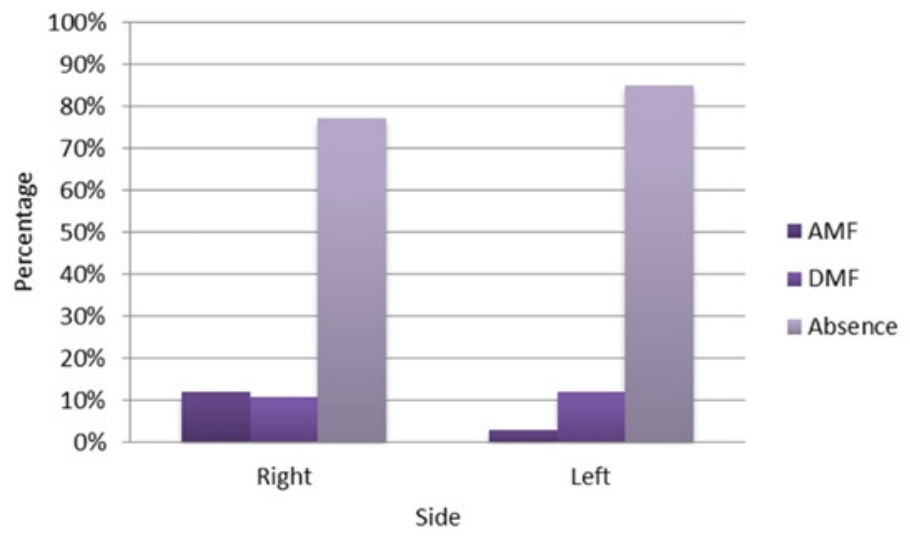

Figure 4. Distribution of types of MF in relation to the side. Absence means the no presence of DMF and/or AMF. AMF: accessory mental foramen; DMF: double mental foramen.

The chi-square test revealed that there was no statistically significant difference for both sex (P value: 0.7066) and for the side (P value: 0.0818 ).

In the evaluated sample, there were no multiple cases such as the triple foramina or overlapping of the DMF and AMF.

\section{Discussion}

In the sample of the Brazilian population studied, two types of foramen were found, namely AMF and DMF. It was found that generally the first has a diameter smaller than half the size of the MF from the same side ${ }^{11}$ and have no direct relationship between the MF featuring different openings. In addition, they have different openings. The DMF has a smaller diameter but it's size with at least half the size of the MF from the same side ${ }^{11}$ and being very close to the MF and with an anteroposterior relationship between them. Both appear in the same opening and there is a bony septum separating them. The highest incidence of AMF found in the literature (55.5\%) was identified in a study of cone beam computed tomography of a Peruvian population ${ }^{17}$.

The presence of the two types of foramen may be associated with the relationship between the mandibular canal and its branches that end in AMF or DMF, this relationship being connected to the canal branching level. The greater proximity between the beginning of the branch and the opening is related to the DMF. As for AMF, it is the greatest distance from the beginning of the branch with the opening.

The results obtained in relation to the sexes indicated $16.9 \%$ of incidence of the AMF in the male sex, while $10.34 \%$ for the same foramen in the female sex. Although there is no statistically significant difference, a trend towards a higher incidence of the AMF in males was observed. For the DMF, it is noted that its existence is found with similar frequency for both sexes, with a discrete direction for the female sex. Male mandibular morphology, with a body generally larger than the female mandible, may be related to the higher frequency of AMF in men ${ }^{18}$. In contrast, female mandibular morphology, with a body generally smaller than the male mandible, may be related to the higher frequency of DMF. Further studies are needed regarding the relationship between $\mathrm{AMF}$ and $\mathrm{DMF}$ with the sexes, since it is possible that the morphology of the mandibles of each sex may be related to the openings directly (DMF) or indirectly (AMF) related to each other.

In addition to the importance of clinical procedures in dentistry, some studies have reported anthropological aspects in the study of these foramina, mainly the AMF. The authors related that the AMF is less frequent in man than in anthropoids. Simonton ${ }^{19}$ found three or four AMF in $39 \%$ of examined orangutans (Pongo pygmaeus), $27 \%$ of examined gorillas (Gorilla gorillas), and $15 \%$ of chimpanzees (Pan troglodytes).

In conclusion, even without showing correlation between sexes and sides, the incidence of AMF and DMF in the studied sample must be considered given the importance of knowledge of the anatomy of these foramina during the execution of anesthetic and surgical procedures in Dentistry.

\section{Acknowledgement}

This study was totally supported by National Council for Scientific and Technological Development (PIBIC/ CNPq) [grant numbers 121504/2019-0].

\section{References}

1. Neves FS, Oliveira SA, Torres MGG, Crusoé-Souza M, Oliveira C, Campos PSF, Crusoé-Rebello I. Accessory mental foramen: case report. RPG Rev Pós Grad. 2010;17(3):173-6.

2. Kqiku L, Sivic E, Weiglein A, Städtler P. Position of the mental foramen: an anatomical study. Wien Med Wochenschr. 2011 May;161(910):272-3.

3. Kim IS, Kim SG, Kim YK, Kim JD. Position of the mental foramen in a Korean population: a clinical and radiographic study. Implant Dent. 2006 Dec;15(4):404-11.

4. Bou Serhal C, Jacobs R, Flygare L, Quirynen M, van Steenberghe D. Perioperative validation of localisation of the mental foramen. Dentomaxillofac Radiol. 2002 Jan;31(1):39-43.

5. Kaffe I, Ardekian L, Gelerenter I, Taicher S. Location of the mandibular foramen in panoramic radiographs. Oral Surg Oral Med Oral Pathol. 1994 Nov;78(5):662-9.

6. Laher AE, Motara F, Wells M. Locating the mental foramen at the bedside with point of care ultrasound imaging. Pan Afr Med J. 2018 Jan 21;29:54.

7. Laher AE, Wells M, Motara F, Kramer E, Moolla M, Mahomed Z. Finding the mental foramen. Surg Radiol Anat. 2016 May;38(4):469-76. 8. Greenstein G, Tarnow D. The mental foramen and nerve: clinical and anatomical factors related to dental implant placement: a literature review. J Periodontol. 2006 Dec;77(12):1933-43.

9. Chrcanovic BR, Abreu MH, Custódio AL. Morphological variation in dentate and edentulous human mandibles. Surg Radiol Anat. 2011 Apr;33(3):203- 13.

10. Mendoza CC, Vasconcelos BCE, Sampaio G, Cauás M, Batista JEM. 
Localização topográfica do forame mandibular: estudo comparativo em mandíbulas humanas secas. Rev Cir Traumatol Buco-Maxilo-Fac. 2004 4(2):137- 142.

11. Oliveira-Santos C, Souza PH, De Azambuja Berti-Couto S, Stinkens L, Moyaert K, Van Assche N, Jacobs R. Characterisation of additional mental foramina through cone beam computed tomography. J Oral Rehabil. 2011 Aug;38(8):595-600.

12. Paraskevas G, Mavrodi A, Natsis K. Accessory mental foramen: an anatomical study on dry mandibles and review of the literature. Oral Maxillofac Surg. 2015 Jun;19(2):177-81.

13. Hanihara T, Ishida H. Frequency variations of discrete cranial traits in major human populations. IV. Vessel and nerve related variations. J Anat. 2001 Sep;199(Pt 3):273-87.

14. Iwanaga J, Watanabe K, Saga T, Tabira Y, Kitashima S, Kusukawa J, Yamaki K. Accessory mental foramina and nerves: Application to periodontal, periapical, and implant surgery. Clin Anat. 2016
May;29(4):493-501.

15. Naitoh M, Hiraiwa Y, Aimiya H, Gotoh K, Ariji E. Accessory mental foramen assessment using cone-beam computed tomography. Oral Surg Oral Med Oral Pathol Oral Radiol Endod. 2009 Feb;107(2):289-94. 16. Aytugar E, Özeren C, Lacin N, Veli I, Çene E. Cone-beam computed tomographic evaluation of accessory mental foramen in a Turkish population. Anat Sci Int. 2019 Jun;94(3):257-265.

17. Cabanillas Padilla J, Quea Cahuana E. Morphological and morphometric study of the mental foramen using cone-beam CT in dentate adult patients. Odontoestomatología. 2014; 16(24):4-12.

18. Subramanian B, Anthony SN, Mubbunu L, Hachombwa C, Mlawa MS, Majambo MM, Sasi RM. Anthropometrics Analysis of Mental Foramen and Accessory Mental Foramen in Zambian Adult Human Mandibles. ScientificWorldJournal. 2019 Jul 16;2019:9093474.

19. Simonton FV. Mental foramen in the anthropoids and in man. Am J Phys Anthrop. 1923; 6:413-421.

\section{Mini Curriculum and Author's Contribution}

1. Luciane Naomi Oguma Watanabe - DDS, MSc student. Contribution: effective scientific and intellectual participation of the study, responsible for literature review on database, data collection, data organization, data interpretation, preparation and draft of the manuscript, critical review and final approval.

ORCID: 0000-0001-5208-0311

2. Alexandre Rodrigues Freire - DDS, MSc, PhD. Contribution: effective scientific and intellectual participation of the study, data interpretation, preparation and draft of the manuscript, critical review and final approval.

ORCID: 0000-0002-0175-0896

3. Juliana Haddad - BS, MSc, PhD student. Contribution: effective scientific and intellectual participation of the study, data collection, data interpretation, preparation and draft of the manuscript, critical review and final approval.

ORCID:0000-0001-6356-8726

4. Paulo Roberto Botacin - DDS, MSc, PhD. Contribution: effective scientific and intellectual participation of the study, data interpretation, preparation and draft of the manuscript, critical review and final approval.

ORCID: 0000-0003-2787-6160

5.Felippe Bevilacqua Prado - DDS, MSc, PhD. Contribution: effective scientific and intellectual participation of the study, data interpretation, preparation and draft of the manuscript, critical review and final approval.

ORCID: 0000-0001-5636-6915

6. Ana Cláudia Rossi - DDS, PhD. Contribution: Guiding professor, responsible for scientific and intellectual participation of the study, responsible for literature review on database, preparation and draft of the manuscript, critical review and final approval.

ORCID: 0000-0002-8718-4898

Received: January 22, 2021

Accepted: April 15, 2021
Corresponding author

Ana Cláudia Rossi

E-mail: rossianac01@gmail.com 